\title{
Siblings with Xeroderma Pigmentosum: A Case Report
}

\author{
TAMANNA BEGUM ${ }^{1}$, ABDUL MANNAN $^{2}$, MD. SHAFIQUE AHAMMED KHAN², SHAHADAT HOSSAIN², \\ AHAMMED ALI ${ }^{3}$
}

\section{Introduction}

Xeroderma pigmentosa (XP) was first described in 1874 by Herba and in 1882 by Kaposi ${ }^{1}$. XP is a very rare autosomal recessive disorder. At present at least 7 forms of XP have been described, each with further subgroups with a slightly different genetic characteristic $^{1,2}$.

The basic defect in XP is in nucleotide excision repair (NER), leading to deficient repair of DNA damaged by ultraviolet radiation (UV) $)^{3,4}$. XP appears to be present throughout the world and it is represented in every ethnic group. There are currently approximately 100 diagnosed cases in $\mathrm{UK}^{4,5}$.

XP usually presents in childhood. The children develop severe and persistent sunburn after their first exposure to the sun. Additional features of $X P$ include photosensitivity, early freckling, areas of skin pigmentation, thin and dry skin, corneal opacities leading to blindness, Neurological damage occur in $20 \%$ cases of XP, it includes deafness, developmental delay, spasticity ${ }^{6,7}$.

The frequency in Europe is approximately 1 case per 250,000 Population. In Japan, it is higher, 1 case per 40,000 population. Cases of XP are reported in all races with equal sex incidence. The disease is usually detected at age 1 or 2 years ${ }^{5,8}$.

As this diseases are very rarely encountered in the paediatric practice, we find it interesting to report two cases who were siblings and were admitted in the department of pediatrics, Begum Khaleda Zia Medical College (BKZMC) and Shaheed Suhrawardy Hospital (SSH), Dhaka.

\section{Case Report}

Shaheen, an 8 year old boy, 2nd issue of consanguineous parents, completely immunized according to EPI schedule was admitted on 12.03.07

1. Associate Professor, Department of Paediatrics, Begum Khaleda Zia Medical College (BKZMC) and Shaheed Suhrawardy Hospital, Dhaka

2. Medical Officer, Department of Paediatrics, Begum Khaleda Zia Medical College (BKZMC) and Shaheed Suhrawardy Hospital, Dhaka

3. Senior Consultant and Head of the Department of Dermatology and Venereology, Begum Khaleda Zia Medical College (BKZMC) and Shaheed Suhrawardy Hospital, Dhaka

Correspondence: Dr. Tamanna Begum with the complaints of pigmentation of the whole body from the age of 2 years, inability to walk from the age of 5 years, watering from eyes and speech problem for same duration.

There was no significant past illness. He was born at home normally with healthy skin and his development was appropriate upto the age of 5 years. Since then he gradually became unable to walk and finally bed ridden. His speech was nasal in character.

On examination, he was mildly anaemic, pigmentation was present all over the body which was more prominent on exposed surfaces like face, limbs and neck (Fig-1, 2). At first it was in the form of frecklings, skin was rough and there were lighter and darker areas in the skin. His Eye examination revealed ptosis, periocular hyper pigmentation with normal visual acuity. On examination of fundus, there was no optic atrophy and pigmentation.

Shaheen was conscious, cooperative, followed the vocal commands but social interaction was poor. Cranial nerves were intact, there was hypertonia, hyper-reflexia which was more marked in lower limb, with extensor planter response. Gait was spastic. Sensory function was intact, cerebellar function showed nystegmus, incoordination of movement and, intention tremor. There was no organomegaly, other systems were normal.

His younger sister, Hafiza (3 years of age) also complains of pigmentation in the whole body from the age of 2 years, which were more prominent on the exposed surfaces like face and extremities. Her hair, nail and teeth were normal. She was intelligent and appeared to be mentally normal for her age. All other systemic finding were normal.

On investigations, $\mathrm{Hb} \%, \mathrm{TC}, \mathrm{DC}$, ESR, Urine, Lipid profile, liver function, renal function tests and serum electrolytes were normal. X-ray of chest, skull, USG of the whole abdomen and ECG were within normal limit.

MRI of brain done for Shaheen showed olivo-pontocerebellar degeneration, evident by mildly enlarged basal cistern, cerebellar fissure, mildly dilated $4^{\text {th }}$ ventricle (Fig-3a), enlarged CSF space and cerebellar atrophy (Fig.-3b in sagital $\mathrm{T}_{1}$ ). Hormone Levels and 


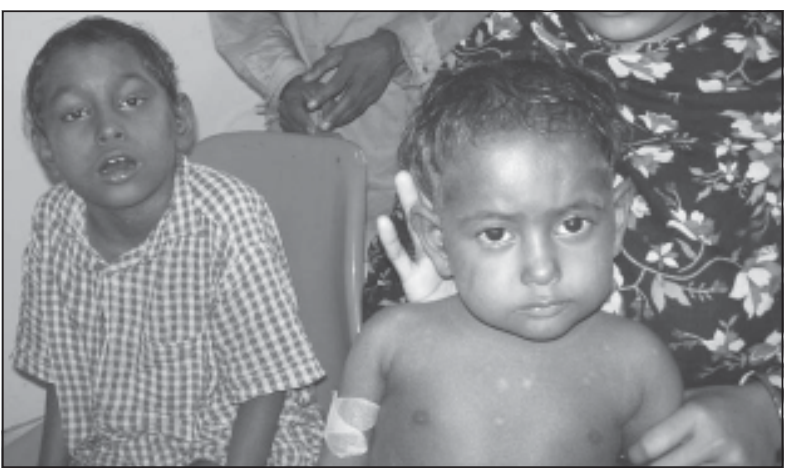

Fig.-1: Photograph of siblings showing pigmentation over face, neck and upper part of chest.

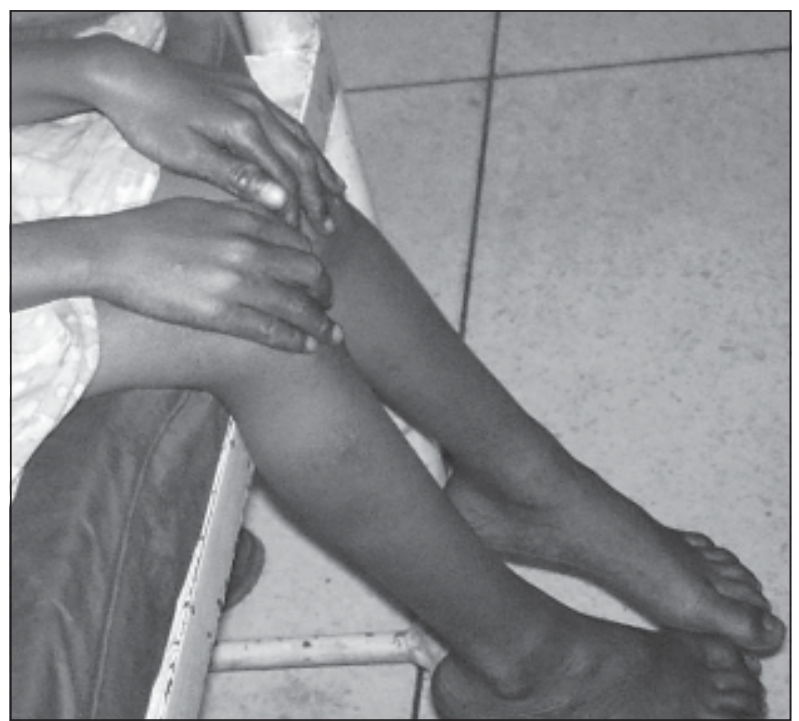

Fig.-2. Showing pigmentation over the exposed part on both the extremities.

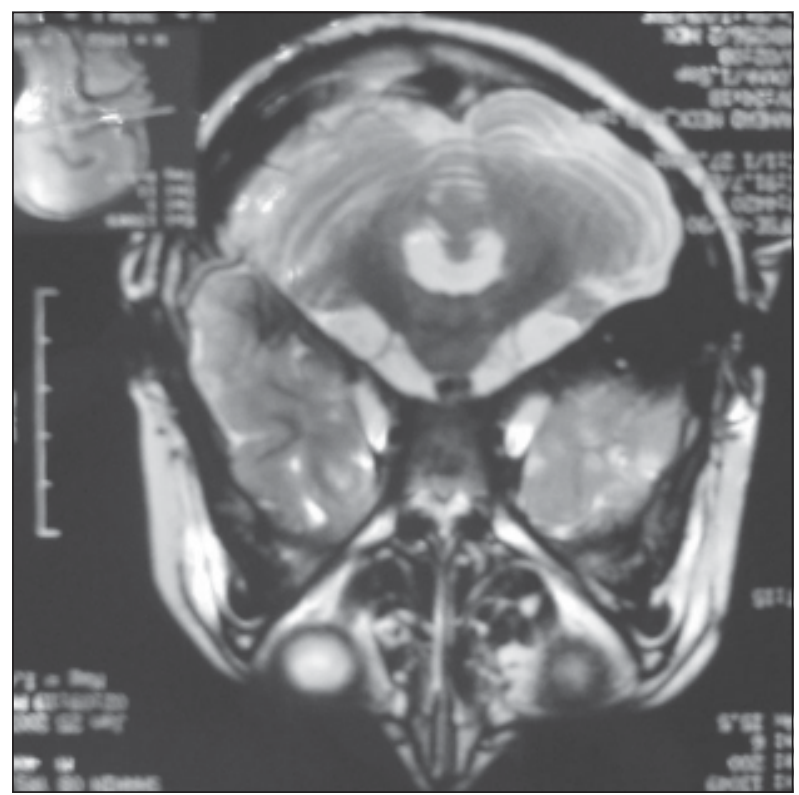

Fig.-3a. MRI report mild dilated basal cistern, $4^{\text {th }}$ ventical mildly dialated.

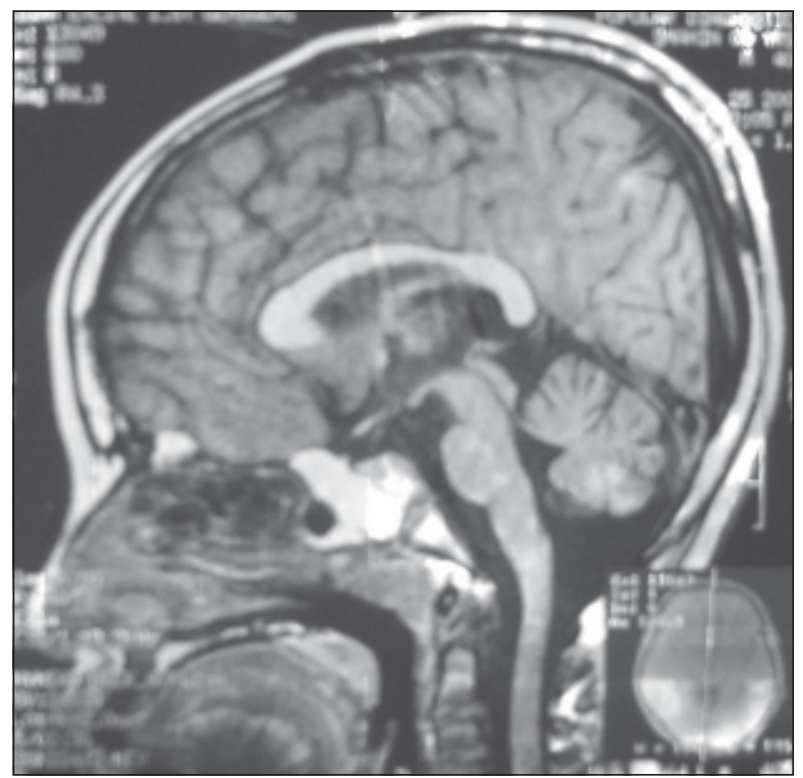

Fig.-3b. Enlarged CSF space, cerebellar atrophy seen in (sagital T1).

iron status was done to exclude other condition like adenoleucodystrophy, chronic haemosiderosis and incontentia pigmenti. ACTH, cortisol, serum iron, total iron binding capacity (TIBC) levels were within normal limit.

Skin biopsy was done for both sibling after consultation with dermatologist. Biopsy showed mildly acanthotic epidermis. The basal layer showed focal increase in melanin pigments. The dermis revealed malanophages, which was compatible with xeroderma pigmentosum.

As there is no specific treatment available for $\mathrm{XP}$, conservative management was advised like avoidance of sun exposure by wearing long sleeve shirts and pants, use of sunglass, sunscreens of SPF of 30 and restricted outdoor activities. Consultation with dermatologist every 3-6 months was advised for early detections of skin cancer. Regular eye examination by ophthalmologist was also advised. Finally, genetic counselling was done.

\section{Discussion}

Xeroderma Pigmentosum (XP) is an autosomal recessive, neurocutaneous disorder characterized by sunlight-induced skin cancers and defective DNA repair. Many XP children develop a primary neuronal degeneration 2,3 . There are 7 complementation groups. Type A,1, XPA Classical form (278700), Type B, 11, XPB (133510), Type C, 111, XPC (278720), Type D,1V, XPD (278730), Type E,V, XPE (278740), Type F,V1, XPF (278760), Type G, V11, XPG (278780) ${ }^{2,3}$. 
Neurological problems are seen in nearly $20 \%$ of patients with XP, more commonly in groups XPA and $X P D^{1,7}$. The problems include microcephaly, spasticity, hyporeflexia or areflexia, ataxia, chorea, motor neuron signs or segmental demyelination, deafness, supra-nuclear ophthalmoplegia, and mental retardation ${ }^{9,10}$.

The neurological problems might overshaddow the cutaneous manifestations in some patients with $\mathrm{XP}^{6}$. $\mathrm{XP}$ variant called De Sanctis-Cacchione syndrome refers to the combination of $\mathrm{XP}$ and neurologic abnormalities including mental retardation and cerebellar ataxia, hypogonadism, and dwarfism ${ }^{2,4,5}$.

Clinical abnormalities in XP were published in different literatures in which median age of the patient was 12 years with equal numbers of male and female patients. Cutaneous symptoms had a median age of onset of between 1 and 2 years. Neurological abnormalities were found in $18 \%$ of cases and ocular involvement in $40 \%$ cases in different study reports ${ }^{3,5}$. Most of the studied findings were co-related with our findings. Many of the XP cases may develope skin malignancies like basal cell carcinoma, squamous cell carcinoma and melanoma ${ }^{6,7}$. The neuropathological study showed marked loss of neurons in the basal nucleus, cerebellum, medulla and spinal cord. Various studies in XP explained their neurological findings being similar to our findings like, olivopontocerebellar atrophy. But the mechanism of CNS damage involved in XP is not described ${ }^{8,9}$. Several reports described siblings born to consanguineous parents, with cutaneous photosensitivity and central nervous system dysfunction consistent with neurological findings and skin findings similar of the reported cases ${ }^{10,11}$.

No consistent routine laboratory abnormalities are present in XP. The diagnosis of XP can be established with studies performed in specialized laboratories. These include cellular hypersensitivity to UV radiation, chromosomal breakage studies and DNA analysis ${ }^{7}$, ${ }^{12}$. But due to non availability of the investigations in our country we could not perform those investigations for the present cases.

There is no curative treatment for XP. The main goal of treatment is to protect ultraviolet exposure and prevent further damage of the skin, avoidance of sun by using cloths and sunscreens. We advised all the preventive measures for our patients Shaheen and Hafiza. Time to time consultation with dermatologist and ophthalmologist was also advised.
The disease is invariably fatal and in most cases death occurs within a few years of its onset ${ }^{1,3}$. Many patients with XP die at an early age from skin cancers. However, if diagnosed early and does not have severe neurological symptoms or has mild variant, and takes all the precautionary measures to avoid exposure to UV light, they may survive beyond middle age ${ }^{6,7}$. Fewer than $40 \%$ of patients may survive beyond the age of 20 years $^{12,13}$.

\section{Conclusion}

$\mathrm{XP}$ is a rare genetic disorder. It is characterized by photosensitivity, pigmentation, eye and neurological involvement. Many patients with XP and their families will face many challenges in daily living. Constant education will help to protect them from sunlight and also early recognitions of skin cancer. Despite all efforts, many suffers will die in early childhood as a result of skin cancer.

\section{References}

1. MarceloG H. Xeroderma Pigmentosum. eMedicine. 2005 June. Available from http:// www.e-medecine.com.

2. Irwin M Braverman. Fitzpatrick's Dermatology in General Medicine. $6^{\text {th }}$ edition, The Mac Graw Hill 2003.

3. Odom RB, James WB, Berger TG. Andrew's Disease of the skin. Clinical dermatology 10 th edition, Saunders Elsevier 2006.

4. Goyal JL, Rao VA, Srinivasan R, Agrawal K. Oculocutaneous manifestations in xeroderma pigmentosa. Br J Ophthalmol 1994; 78: 295-97.

5 Kraemer KH, Lee MM, Scotto J. Xeroderma pigmentosum: cutaneous, ocular and neurologic abnormalities in 830 published cases. Arch Dermatol 1987;123: 241-50.

6. Robbins $\mathrm{JH}$, Brumbach RA, Mendiones $\mathrm{M}$, Barrett SF, Carl JR, Cho S et al. Neurological disease in xeroderma pigmentosum, documentation of a late onset type of the juvenile onset form. Brain 1991; 114: 1335-61.

7. Mimaki T, Itoh N, Abe J,Tagwa T, Sato K, Yabuuchi $\mathrm{H}$ et al. Neurological manifestations in xeroderma pigmentosum. Ann Neurol 1986; 20 : 70-75.

8. Oytta M, Anttinen A. Xeroderma pigmentosum with neurological abnormalities. A clinical and neuropathological study. Acta Neurol Scand 1986; 73: 191-99. 
9. Karu S, Yasuma M, Sakai M, Konagava M, Moriwaki S. Siblings with Xeroderma Pigmentosum group A showing mild cutaneous and various neurological manifestations. J Clinical Neurology 2006; 46: 134-39.

10. Grewal RP. Neuron and DNA repair. Neurologic involvement in Xeroderma pigmentosa. Med hypotheses 1991; 34: 71-73.

11. El-Hayek M, Lestringant GG, Frossard PM. Xeroderma pigmentosum in four siblings with three different types of malignancies simultaneously in one. J Pediatr Hemato Oncol 2004; 26: 473-75.

12. Dubey Arvind Kumar, Nagar Madhu, GuptaAnita, Sahu Dines, Mishra Suboth. Case Report Xeroderma pigmentosum. Indian Journal of Opthalmolog 1990; 38: 94-96.

13. Cleaver JE. Xeroderma pigmentosum; a human disease in which an initial stage of DNA repair is defective. Proc Natl Acad Sci USA 1969; 63: 428-35. 